\title{
Prevalence of cardiovascular malformations and association with karyotypes in Turner's syndrome
}

\author{
C-O Gøtzsche, B Krag-Olsen, J Nielsen, K E Sørensen, B Ø Kristensen
}

\begin{abstract}
The aim of the study was to establish the prevalence of cardiovascular malformations in females with Turner's syndrome and analyse possible associations with the various karyotypes. One hundred and seventy nine of 393 females who had Turner's syndrome diagnosed in Denmark were examined. Complete chromosome analysis was available in all cases. Clinical examination, electrocardiography, and echocardiography including Doppler were performed.

The distribution of the various karyotypes was 45,X, 58\%; mosaic monosomy $X, 35 \%$; and structural abnormalities of the $X$ chromosome, $7 \%$. In $46(26 \%)$ of the females a total of 69 cardiovascular malformations were found; aortic valve abnormality (18\%) and aortic coarctation $(10 \%)$ being the most common. There was a significant difference in the prevalence of cardiovascular malformations between $45, X$ and mosaic monosomy $X(38 \% v$ $11 \%$ ), primarily due to a significant difference in the prevalence of aortic valve abnormalities and aortic coarctation. Pulmonary valve abnormalities were seen only in females with mosaic monosomy $X$ but the prevalence was low $(3 \%)$. No patient with structural abnormalities of the $\mathbf{X}$ chromosome had cardiovascular malformations.
\end{abstract}

(Arch Dis Child 1994; 71: 433-436)

Turner's syndrome is a genetic abnormality in females and the karyotype can be monosomy $\mathrm{X}(45, \mathrm{X})$, mosaic monosomy $\mathrm{X}$, or a structural abnormality of the $\mathrm{X}$ chromosome. The syndrome is characterised by short stature and gonadal dysgenesis, and is associated with a number of congenital abnormalities including cardiovascular malformations. In published series of Turner's syndrome the percentage of those with cardiovascular malformations has ranged from $17 \%$ to $47 \%$; aortic coarctation and bicuspid aortic valve being the most common lesions. ${ }^{1-3}$ However, these studies have all been relatively small hospital based series from departments of paediatrics, cardiology, or endocrinology. Due to possible selection bias, these data may not truly reflect the prevalence of cardiovascular malformations in

An association of aortic valve disease and aortic coarctation with 45,X karyotype and pulmonary stenosis with mosaic monosomy $\mathrm{X}$ has previously been suggested, ${ }^{4}$ but prevalence
Since 1963, all females with Turner's syndrome diagnosed in Denmark have been listed in the Danish National Cytogenetic Register. The presence of this register made it possible for us to examine a large and relatively unselected group of females with Turner's syndrome. The introduction of echocardiography with the application of Doppler techniques has made non-invasive detection of cardiovascular malformations possible, including identification of minor cardiac lesions that may otherwise remain asymptomatic for years. Doppler ultrasonographic modalities have not been used in previous studies of females with Turner's syndrome.

The purpose of our study was to establish the prevalence of cardiovascular malformations and investigate any possible associations between the various genotypes and cardiovascular malformations.

\section{Patients and methods}

In March 1988, 393 females with Turner's syndrome were registered in the Danish National Cytogenetic Register. We were able to obtain contact with 223 through direct contact, through the family doctor, or through the National Association of Turner Contact Groups, and 179 agreed to participate. The mean age of the females examined was 23 years (range 6 months to 46 years). Results from chromosome analysis were available in all.

In each case a history was taken concerning cardiovascular symptoms and former operations. Clinical examination, electrocardiography, and echocardiography were performed by a cardiologist blinded to the specific karyotype.

Echocardiography including Doppler studies was performed using a Toshiba 60 or $65 \mathrm{~A}$. Pulsed and continuous wave Doppler as well as colour flow mapping was performed with a $2.5 \mathrm{MHz}$ transducer. The echocardiography included standard $M$ mode measurements and two dimensional evaluation from all standard planes. Flow velocities across the aortic, mitral, pulmonary, and tricuspid valve as well as in the ascending and descending thoracic aorta were obtained using pulsed and continuous Doppler modalities. ${ }^{5}$ All echocardiograms were recorded on videotape and later reviewed blindly by another cardiologist. The diagnosis of bicuspid aortic valve and mitral valve prolapse followed standard criteria. ${ }^{26}$

The $\chi^{2}$ test with the Yates's correction and Fisher's exact test were used in comparison between the 45, $\mathrm{X}$ group and the mosiac monosomy $\mathrm{X}$ group; $\mathrm{p}<0.05$ was considered significant. Turner's syndrome. studies are not available.

\footnotetext{
Correspondence to: Dr Kristensen.

Accepted 17 August 1994

Aarhus University of Cardiology, Skejby and Cytogenetic of Biological Denmark B Krag-Olsen J Nielsen
}$$
\text { studies are not available. }
$$ 
Table 1 Distribution of karyotypes in 179 females with Turner's syndrome

\begin{tabular}{|c|c|c|c|}
\hline & Karyotypes & No & \\
\hline \multirow{2}{*}{$\begin{array}{l}\text { Complete monosomy } \\
\text { Mosaic monosomy X }\end{array}$} & $45, X$ & & $\begin{array}{l}103 \\
63\end{array}$ \\
\hline & $\begin{array}{l}\text { 45,X/46,XX } \\
\text { 45,X/46,X,r(X) } \\
\text { 45,X/46,X,i(Xq) } \\
\text { 45,X/46,XY } \\
\text { 45,X/46,X+mar } \\
\text { 45,X/47,XXX } \\
\text { 45,X/46,X,dic(Xq) } \\
\text { 45,X/46,X,i(Xq)/47,X,i(Xq),i(Xq) } \\
\text { 45,X/46,X,del(X)(p11) } \\
\text { 45,X/46,X,del(X)(q11) } \\
\text { 45,X/46,X,i(Yp) } \\
\text { 45,X/46,X,dic(X;X)(p22;p22) } \\
\text { 45,X/46,Xinv(X)(p22;q24) } \\
\text { 45,X/46,X,i(Xq)/46,X,r(X) } \\
\text { 46,XX/46,X,i(Xq) }\end{array}$ & $\begin{array}{r}14 \\
13 \\
13 \\
3 \\
3 \\
3 \\
3 \\
3 \\
2 \\
1 \\
1 \\
1 \\
1 \\
1 \\
1\end{array}$ & \\
\hline $\mathrm{X}$ structural abnormalities & $\begin{array}{l}\text { 46,XX,i(Xq) } \\
46, X, \operatorname{del}(\mathbf{X})(\mathrm{p} 11) \\
46, X, \operatorname{del}(\mathbf{X})(\mathrm{q} 25) \\
46, X, \operatorname{del}(\mathbf{X})(\mathrm{q} 13) \\
46, X,+\operatorname{mar} \\
46, X, \operatorname{dic}(X ; X)(\mathrm{p} 21 ; \mathrm{p} 21)\end{array}$ & $\begin{array}{l}7 \\
2 \\
1 \\
1 \\
1 \\
1\end{array}$ & 13 \\
\hline
\end{tabular}

The study was approved by the local ethical committee for medical science.

\section{Results}

Of the 179 subjects examined $103(58 \%)$ had complete monosomy X, 63 (35\%) had mosaic monosomy X, and $13(7 \%)$ had a structural X chromosome abnormality (table 1). In 46 $(26 \%)$ females a total of 69 cardiovascular malformations were found (table 2). Aortic valve abnormalities were seen in $33(18 \%)$, the valve being bicuspid and/or stenosed and/or regurgitant. Bicuspid aortic valve was the most common malformation being detected in 25 $(14 \%)$. Eight of the bicuspid valves were either stenotic and/or incompetent. Of eight females with aortic stenosis four had a bicuspid aortic valve, and of the 11 with aortic regurgitation four had a trileaflet aortic valve with no morphological abnormality detected on two dimensional evaluation. Aortic coarctation was found in $18(10 \%)$, all located in the typical position in the descending thoracic aorta.

Among subjects with 45,X karyotype 39 $(38 \%)$ had cardiovascular malformations, while this was found in only seven $(11 \%)$ with mosaic monosomy $X \quad(p<0.001)$. No cardiovascular malformations were found in the small group with a structural $\mathrm{X}$ chromosome abnormality. The association between the cardiovascular malformations and karyotypes is shown in table 3 . In subjects with $45, X$, aortic coarctation was more prevalent than in mosaic monosomy $X$ : $17 \%$ v $2 \%(\mathrm{p}<0.01)$. Aortic valve abnormalities were seen in $29(28 \%)$ females with 45 , $\mathrm{X}$, but only in four (7\%) with mosaic monosomy $X(p<0.001)$. Ten $(10 \%)$ subjects had malformations in more than one cardiovascular site and all had the 45,X karyotype $(p<0 \cdot 05)$.

Table 2 Cardiovascular malformations in 46 females with Turner's syndrome

\begin{tabular}{|c|c|c|c|c|c|c|c|}
\hline \multirow[b]{2}{*}{$\begin{array}{l}\text { Patient } \\
\text { No }\end{array}$} & \multirow[b]{2}{*}{$\begin{array}{l}\text { Age } \\
\text { (years) }\end{array}$} & \multirow[b]{2}{*}{ Karyotype } & \multicolumn{5}{|c|}{ Type of cardiovascular malformation } \\
\hline & & & $\begin{array}{l}\text { Aortic } \\
\text { coarctation }\end{array}$ & $\begin{array}{l}\text { Bicuspid } \\
\text { aortic } \\
\text { valves }\end{array}$ & $\begin{array}{l}\text { Aortic } \\
\text { stenosis }\end{array}$ & $\begin{array}{l}\text { Aortic } \\
\text { regurgitation }\end{array}$ & Other \\
\hline 1 & 24 & $45, \mathrm{X}$ & + & & & + & \\
\hline 2 & 31 & $45, \mathrm{X}$ & & + & & & \\
\hline 3 & 23 & $45, \mathrm{X}$ & + & & + & + & \\
\hline 4 & 39 & $45, \mathrm{X}$ & & & & + & \\
\hline 5 & 16 & $45, x$ & + & & & & \\
\hline 6 & 19 & $45, x$ & + & + & & & \\
\hline 7 & 11 & $45, x$ & + & & & & \\
\hline 8 & 6 & $45, X$ & & + & & & \\
\hline 9 & 9 & $45, \mathrm{X}$ & + & & & & Mitral regurgitation \\
\hline 10 & 35 & $45, x$ & & + & & + & \\
\hline 11 & 22 & $45, x$ & + & & & & \\
\hline 12 & 8 & $45, x$ & + & + & & & PDA \\
\hline 13 & 5 & $45, x$ & & + & + & & \\
\hline 14 & 32 & $45, \mathrm{X}$ & + & & & + & \\
\hline 15 & 24 & $45, \mathrm{X}$ & & + & & & \\
\hline 16 & 46 & $45, X$ & & & + & & \\
\hline 17 & 16 & $45, X$ & & + & + & + & \\
\hline 18 & 21 & $45, \mathrm{X}$ & & + & & & \\
\hline 19 & 37 & $45, X$ & & + & & & \\
\hline 20 & 15 & $45, x$ & & + & & & Dextrocardia \\
\hline 21 & 26 & $45, x$ & + & + & & & \\
\hline 22 & 25 & $45, \mathrm{X}$ & & + & & & \\
\hline 23 & 31 & $45, x$ & & + & & & \\
\hline 24 & 30 & $45, x$ & + & & & & \\
\hline 25 & 14 & $45, \mathrm{X}$ & & + & & & \\
\hline 26 & 39 & $45, \mathrm{X}$ & + & & & & \\
\hline 27 & 11 & $45, \mathrm{X}$ & + & & & & \\
\hline 28 & 22 & $45, x$ & + & & & & \\
\hline 29 & 24 & $45, x$ & & + & & & \\
\hline 30 & 8 & $45, \mathrm{X}$ & & & + & & \\
\hline 31 & 4 & $45, \mathrm{X}$ & + & & & & PDA, PAPVD \\
\hline 32 & 18 & $45, x$ & + & + & & + & \\
\hline 33 & 25 & $45, \mathrm{X}$ & & + & & + & \\
\hline 34 & 17 & $45, X$ & & + & & & \\
\hline 35 & 16 & $45, x$ & & & & + & \\
\hline 36 & 22 & $45, \mathrm{x}$ & + & & & & \\
\hline 37 & 3 & $45, x$ & & & + & + & \\
\hline 38 & 29 & $45, x$ & & + & & + & \\
\hline 39 & 20 & $45, x$ & & + & & & \\
\hline 40 & 44 & $45, X / 46 X Y$ & & + & + & & \\
\hline 41 & 19 & $45, X / 46 X X$ & + & & & & \\
\hline 42 & 22 & $45, X / 46, X i(X q)$ & & + & & & \\
\hline 43 & 10 & $45, \mathrm{X} / 46, \mathrm{Xr}(\mathrm{X})$ & & & & & Pulmonary stenosis \\
\hline 44 & 42 & $45, X / 46, X i(X q)$ & & + & + & & \\
\hline 45 & 17 & $45, \mathrm{X} / 46, \mathrm{Xi}(\mathrm{Yp})$ & & & & & Pulmonary regurgitation \\
\hline 46 & 7 & $45, X / 46, X i(X q) / 47, X i(X q)$ & & + & & & \\
\hline
\end{tabular}


Table 3 Number (\%) of females with cardiovascular malformations in the different karyotypes of Turner's syndrome

\begin{tabular}{lll}
\hline & \multicolumn{2}{l}{ Karyotypes } \\
\cline { 2 - 3 } Cardiovascular malformations & $45, X(n=103)$ & Mosaic monosomy $X(n=63)$ \\
\hline Aortic valve abnormality & $21(20)$ & $4(6)$ \\
Coarctation & $8(8)$ & $1(2)$ \\
Coarctation + aortic valve abnormality & $6(6)$ & 0 \\
Coarctation+OCM & $3(3)$ & 0 \\
Aortic valve abnormality +OCM & $1(1)$ & 0 \\
Pulmonary valve abnormality & 0 & $2(3)$ \\
Total & $39(38)$ & $7(7)$ \\
\hline
\end{tabular}

$\mathrm{OCM}=$ other cardiovascular malformations

No females with structural abnormalities of the $\mathrm{X}$ chromosome $(n=13)$ had cardiovascular malformations. mately $35 \%$ of the total population with Turner's syndrome, the rest remaining undiagnosed. In the major subgroup of females with undiagnosed Turner's syndrome it seems reasonable to expect a somewhat lower prevalence of cardiovascular malformations as clinical signs or symptoms have not resulted in karyotype examination. On the other hand children with Turner's syndrome and cardiovascular malformations may die in utero or in the neonatal period, for example, patients with severe aortic coarctation.

Bicuspid aortic valve is thought to be the most common cardiovascular malformation in the general population occurring in $1 \%$ to $2 \% .{ }^{10}$ In previous echocardiographic studies the prevalence of bicuspid aortic valve in Turner's syndrome has ranged from $9 \%$ to $34 \% .^{2} 311 \mathrm{We}$ found bicuspid aortic valves in 14\%. Adding females with aortic stenosis and/or regurgitation without a bicuspid valve a total of $18 \%$ had abnormal aortic valves. It is generally agreed that a bicuspid aortic valve predisposes to valvular stenosis and/or insufficiency with advancing age, ${ }^{12}$ and indeed $32 \%$ of those with bicuspid aortic valve had either stenosis or insufficiency of the valve. Apart from the haemodynamic consequence of an abnormal valve, susceptibility to infective endocarditis warrants antibiotic prophylactic treatment.

The prevalence of aortic coarctation has varied in previous studies from $2 \%$ to $19 \% .^{1-3}$ We found $10 \%$ with aortic coarctation. In the Danish population in general the prevalence is $0.042 \%{ }^{13}$ The prevalence of mitral valve prolapse in healthy young women is assumed to be $1 \%$ to $2 \%{ }^{14}$ An extremely high occurrence of mitral valve prolapse in Turner's syndrome has been found in one study, ${ }^{3}$ but using a standard definition we were not able to find any subject with this malformation.

Even though two studies have suggested an increased prevalence of cardiovascular malformations in females with $45, \mathrm{X}$ compared with females with Turner's syndrome and other genotypes ${ }^{14}$ a detailed analysis of prevalence has never been reported. Nora et al examined 36 females with Turner's syndrome and known cardiovascular disease and found an association between mosaic monosomy $\mathrm{X}$ and pulmonary stenosis, and between $45, \mathrm{X}$ and aortic coarctation. ${ }^{4}$ No abnormalities of the aortic valve were found in their study from the pre-echocardiographic era. In our study, the prevalence of cardiovascular malformations was significantly higher in 45, X karyotype $(38 \%)$ than in mosaic monosomy X $(11 \%)$. No subject with structural abnormalities of the $\mathrm{X}$ chromosome had cardiovascular malformations. Looking into the specific cardiovascular malformations a significantly higher prevalence of aortic coarctation and aortic valve abnormality was found in the $45, \mathrm{X}$ group, and the combination of aortic coarctation and aortic valve abnormality was only seen in subjects with this karyotype. In contrast, two females with pulmonary valve disease both had mosaic monosomy $\mathrm{X}$, suggesting an association between pulmonary valve disease and mosaic monosomy $\mathrm{X}$, but the prevalence is low. Cytogenetic Register includes all patients with diagnosed Turner's syndrome we can estimate that females enlisted represent only approxi- 
In a selected group of females with Turner's syndrome, Price et al found a reduction in life expectancy, particularly because of death due to cardiovascular malformations. ${ }^{15}$ Furthermore, a few young women with Turner's syndrome and no evidence of cardiovascular disease who died from dissection of the aorta have been reported. ${ }^{16}$ This may indicate an association between Turner's syndrome and weakness of the aortic wall. We conclude that Turner's syndrome is associated with a substantial increase in the prevalence of cardiovascular malformations primarily related to the 45,X karyotype. Aortic valve disease and aortic coarctation are the most common malformations and they are significantly more frequent in 45,X karyotype. Because of the therapeutic and prophylactic implications we recommend a cardiological examination including Doppler echocardiography in all females with Turner's syndrome, once the diagnosis is established.

The study was supported by a grant from the Danish Heart Foundation. We are also grateful to members of the National Association of Turner Contact Groups who assisted in the study.

1 Rainer-Pope CR, Cunningham RD, Nadas AS, Crigler JF. Cardiovascular malformations in Turner's syndrome. Pediatrics 1964; 19: 919-25.

2 Mazzanti L, Prandstaller D, Tassinara D, et al. Heart disease in Turner's syndrome. Helv Paediatr Acta 1988; 43: 25-31.

3 Bastianon V, Pasquino AM, Giglioni E, et al. Mitral valve prolapse in Turner syndrome. Eur $\mathcal{F}$ Pediatr 1989; 148: 533-4

4 Nora JJ, Torres FG, Sinha AK, McNamara DG. Characteristic cardiovascular anomalies of XO Turner syndrome, $\mathrm{XX}$ and $\mathrm{XY}$ phenotype and $\mathrm{XO} / \mathrm{XX}$ Turner mosaic. Am $\mathcal{F}$ Cardiol 1970; 25: 639-41.

5 Goldberg SJ, Allen HD, Marx GR, Donnerstein RL. Doppler echocardiography. 2nd Ed. Philadelphia: Lea and Febpler echocar, 1988

6 Perloff JK, Child JS, Edwards JE. New guidelines for the clinical diagnosis of mitral valve prolapse. Am $\mathcal{f}$ Cardiol

7 Palmer CG, Reichmann A. Chromosomal and clinical findings in 110 females with Turner syndrome. Hum Genet 1976; 35: 35-49.

8 Hall JG, Gilchrist DM. Turner syndrome and its variants. Pediat Clin North Am 1990; 37: 1421-40.

9 Nielsen J, Wohlert $M$. Sex chromosome abnormalities found among 34910 newborn children: results from a 13year incidence study in Århus, Denmark. Birth Defects 1991; 26: 209-23.

10 Roberts WC. The congenitally bicuspid aortic valve. A study of 85 autopsy cases. Am 7 Cardiol $1970 ; 26: 72-83$.

11 Miller MJ, Geffner ME, Lippe BM, et al. Echocardiography reveals a high incidence of bicuspid aortic valve in Turner syndrome. F Pediatr 1983; 102: 47-50.

12 Braunwald E. Valvular heart disease. In: Brunwald W, ed. Heart disease. A textbook of cardiovascular medicine. 4th Ed. Philadelphia: WB Saunders, 1992: 1035.

13 Bækgaard-Laursen $H$. Congenital heart disease in Denmark, 1963-73. An epidemiological investigation. [Thesis.] Copenhagen: FADL's forlag, 1979.

14 Wann LS, Grove JR, Hess TR, et al. Prevalence of mitral prolapse by two dimensional echocardiography in healthy young women. Br Heart f 1983; 49: 334-40.

15 Price WH, Clayton JF, Collyer S, deMey R, Wilson J. Mortality ratios, life expectancy, and causes of death in patients with Turner's syndrome. $f$ Epidemiol Community Health 1986; 40: 97-102.

16 Price WH, Wilson J. Dissection of the aorta in Turner's syndrome. $\mathcal{F}$ Med Genet 1983; 20: 61-3. 